\title{
The Credibility of the European monetary System:
} A Review*

\section{Francisco Ledesma Rodríguez}

Universidad de La Laguna

\section{Manuel Navarro Ibáñez}

Universidad de La Laguna

\section{Jorge Pérez Rodríguez}

Universidad de Las Palmas de Gran Canaria

\section{Simón Sosvilla Rivero}

Universidad Complutense de Madrid

FEDEA. Jorge Juan, 46. 28001 Madrid

simon.sosvilla@fedea.es

\begin{abstract}
The paper presents an overview of several studies about the credibility of the European Monetary System (EMS). These studies compare different credibility indi-

* The authors are very grateful to the editor and two anonymous referees for useful comments and suggestions on a previous draft of this paper, substantially improving the content and quality of the paper. Financial support from the Spanish Ministry of Science and Technology (SEJ2005-09094/ECON) is also gratefully acknowledged. The views expressed here are those of the authors and not necessarily those of the institutions with which they
\end{abstract}


cators in terms of their ability to detect exchange rate crises in a target zone. Marginal credibility seems to be the best measure for capturing the main events. The credibility indices are also applied to the first years of the current ERM-II. The history of the EMS suggests that, in an environment of financial deregulation and high capital flows, such an exchange rate system can only operate as a temporary regime that is moving towards a full monetary union, since it may be too fragile as a permanent monetary regime.

Keywords: Credibility, Exchange Rates, Target Zones, European Monetary System.

JEL Classification: C52, F31

\section{INTRODUCTION}

The fall of the Bretton Woods System in the early 1970's and the resulting volatility in financial markets led some Western European countries to create an area of monetary stability. First, they created the so-called Snake (which included European Community (EC) and non-EC members), and later, in March of 1979, a multilateral parity grid, the European Monetary System (EMS), which showed a profound commitment to stabilizing exchange rates. It was believed that, under floating rates, short-term exchange rate volatility was excessive and that medium-term misalignments seemed to discourage trade and investment flows.

The EMS is the most prominent example of a target zone exchange rate system. Starting with the seminal work by Krugman (1991), a large number of papers have examined the dynamics of exchange rates in target zones (see Kempa and Nelles, 1999 , for a review). The main result of the target zone model is that, with perfect credibility, the zone exerts a stabilizing effect (the so-called «honeymoon» effect), reducing the exchange rate sensitivity to a given change in economic fundamentals. Nevertheless, in a target zone with credibility problems, expectations of future interventions tend to destabilize the exchange rate, making it less stable than the underlying fundamentals (Bertola and Caballero, 1992). Credibility seems to be a critical issue for explaining how successful a target zone is.

A target zone needs to rely on some degree of policy cooperation among its members. The failure to cooperate may easily transform market pressure into an exchange rate crisis. The literature on the EMS experience seems to confirm the importance of policy disagreements as a determinant of speculative pressure and realignments (Edin 
and Vredin, 1993; De Grauwe, 2000). A case in point occurred following the German unification, which led to high interest rates at a time when other EMS states were in the midst of a recession.

Credibility can be defined as the degree of confidence that economic agents assign to the announcements made by policymakers. In the context of an exchange rate target zones like the EMS, credibility refers to the perception of agents with respect to the commitments to maintain the exchange rate around a central parity. Therefore, the possibility that the official authorities alter the central rate could be anticipated by the economic agents, triggering expectations of future modifications in the exchange rate that could act as a destabilizing element of the system.

Recognizing the importance of credibility in the evaluation of the costs and benefits of a target zone, in the aim of this paper is to provide an overview of several studies about the credibility of three of the weakest currencies that participated in the EMS (the Spanish peseta, the Portuguese escudo, and the Irish pound) ${ }^{1}$, as well as to present a joint analysis of credibility of weak and hard currencies. Although the EMS has been analysed extensively, these studies diverge from previous research, as they make use of different credibility indicators that have been proposed in the literature, to measure the economic agents' perception towards the EMS commitments. Moreover, one of the papers covers all the EMS countries, except Finland and Luxembourg, and examines the complete EMS history (Ledesma-Rodríguez et al, 2005), including events such as the monetary turmoil at the end of 1992 and the broadening of fluctuation bands in August of 1993.

The structure of the rest of the paper is as follows: Section II reviews the structure and operation features of the EMS and offers a brief account of its historical evolution. Section III presents the credibility indicators used in the literature surveyed. Section IV contains the empirical results, as well as the comparison of the prediction qualities of the indicators. Finally, Section V offers some concluding remarks.

are affiliated.

${ }^{1}$ Ledesma-Rodríguez et al. (2001) also study four core ERM currencies (the French 


\section{The EMS}

The EMS was created on account of a Resolution of the European Council on the 5th December 1978. From its inception, the EMS grouped the main Western European countries (now exclusively EC), except the U.K., with the intention of reducing exchange rate volatility, and in that way set the scenario that would lead to a closer economic and financial articulation. Monetary integration was viewed as an indispensable element of economic integration, for excessive exchange rate volatility disrupted economic policies and threatened to erode political support for the customs union. The move to a Single Market made it even more obvious that exchange rate fluctuations impede true economic integration.

Monetary integration was also an instrument for pushing forward political integration. It was expected that the members that joined the Exchange Rate Mechanism (ERM) in 1979 would eventually tighten their commitments and so provide the best starting point for the transition to (what later became) the Economic and Monetary Union (EMU). The basic characteristic of the ERM, an adjustable peg system, was that each participating currency had a target zone, which involved setting prescribed limits on the range of values (around a central parity expressed in terms of the European Currency Unit ${ }^{2}$ ) that the exchange rate was allowed to take. To keep the rate within those limits, the member states were obliged to intervene in the foreign exchange market if a currency approached the limits of its allowable range. For this purpose, the EMS provided for special credit facilities. Realignments of the central parity by the monetary authority were possible, provided that all the members of the EMS agreed. This provision meant that «policy harmonization did not consign governments to a macroeconomic strait jacket» (Eichengreen, 2000, p. 5).

The fluctuation bands were originally set at $\pm 2.25 \%$, but a $\pm 6 \%$ range was set for Italy and the latecomers: Spain, United Kingdom and Portugal. After almost a year of unprecedented turmoil in the short history of the EMS, at the beginning of August of 1993, Europe's central bank governors and finance ministers widened the ERM's bands to $\pm 15 \%$ (except in the case of the Dutch guilder and the Deutschmark, which remained within the narrow range of $\pm 2.25 \%$ ). There were fifty-eight realignments of

franc, the Danish krone, the Belgian franc, and the Dutch guilder), all with respect to the German mark. 
central parities during the history of the EMS, i.e., 1979-1998, implemented in nineteen discrete adjustments.

The history of the EMS can be divided in four main periods that correspond to main changes in the operation of the ERM. The first one spans the first seven years of operation: from the inception of the ERM in March 1979 to January of 1987, and is characterized by frequent realignments (up to eleven) to correct the divergence in economic fundamentals of the member states. The second period lasted from 1987 to 1992, and coincided with increasing confidence in the ERM, with the removal of controls on cross-border capital flows, and with greater convergence in economic fundamentals. Since there were no realignments ${ }^{3}$ during this period, some commentators began to talk about a «new» EMS, one with a more rigid peg (Giavazzi and Spaventa, 1991).

The third period covers the successive crises from September 1992, which took the British pound and the Italian lira out of the ERM, up to the broadening of the fluctuation bands in August 1993. The German unification shock and its consequent impact on the European economy (already in a severe recession), the increased financial risks due to the removal of capital controls and the surge in bank lending are widely seen as the underlying causes of these crises. The last period opened up with the widening of the bands to $\pm 15 \%$, and was characterized by a decrease in volatility to levels comparable to those prevailing before 1992 (Ayuso et al., 1994; Sosvilla-Rivero et al., 1999). The EMS ended with the adoption of a single currency, the euro, and a common central bank by eleven member states on January 1999. Table 1 summarizes all the realignments and other changes which occurred during the history of the ERM.

Table 1. Main realignments and changes in the ERM (1979-1998)

\begin{tabular}{|l|l|}
\hline 13.3 .1979 & $\begin{array}{l}\text { ERM starts with BFR, DKR, DM, FF, IRL, LIT and HFL. They all are within the } \\
\text { narrow band ( } \pm 2.25 \% \text { fluctuation), except LIT }( \pm 6 \% \text { fluctuation). }\end{array}$ \\
\hline 24.9 .1979 & Realignment (DKR $-3 \%, \mathrm{DM}+2 \%)$. \\
\hline 30.11 .1979 & Realignment (DKR $-5 \%)$. \\
\hline $23.3,1981$ & Realignment (LIT $-6 \%)$. \\
\hline 5.10 .1981 & Realignment (DM $+5.5 \%, \mathrm{FF}-3 \%, \mathrm{HFL}+5.5 \%, \mathrm{LIT}-3 \%)$. \\
\hline
\end{tabular}

2 The European Currency Unit, better known as ECU, was a basket of the (differently weighted) currencies included in the ERM. It was the predecessor of the euro. 
Table 1 (cont.). Main realignments and changes in the ERM (1979-1998)

\begin{tabular}{|c|c|}
\hline 22.2.1982 & Realignment (BFR $-8.5 \%$, DKR $-3 \%$ ). \\
\hline 14.6.1982 & Realignment (DM +4.25\%, FF $-5.75 \%$, HFL $+4.25 \%$, LIT $-2.75 \%)$ \\
\hline 22.3 .1983 & $\begin{array}{l}\text { Realignment (BFR }+1.5 \%, \mathrm{DKR}+2.5 \%, \mathrm{DM}+5.5 \%, \mathrm{FF}-2.5 \% \text {, IRL }-3.5 \% \text {, } \\
\mathrm{HFL}+3.5 \%, \mathrm{LIT}-2.5 \%)\end{array}$ \\
\hline 22.7.1985 & $\begin{array}{l}\text { Realignment (BFR }+2 \%, \text { DKR }+2 \%, \mathrm{DM}+2 \%, \mathrm{FF}+2 \%, \mathrm{IRL}+2 \%, \mathrm{HFL}+2 \% \text {, } \\
\text { LIT }-6 \%) \text {. }\end{array}$ \\
\hline 7.4.1986 & Realignment $(\mathrm{BFR}+1 \%, \mathrm{DKR}+1 \%, \mathrm{DM}+3 \%, \mathrm{FF}-3 \%, \mathrm{HFL}+3 \%)$ \\
\hline 4.8 .1986 & Realignment (IRL $-8 \%)$. \\
\hline 12.1.1987 & Realignment (BFR $+2 \%, \mathrm{DM}+3 \%, \mathrm{HFL}+3 \%)$. \\
\hline 19.6.1989 & The PTA joins the ERM with the wide band $( \pm 6 \%)$. \\
\hline 8.1 .1990 & The LIT joins the narrow band $( \pm 2.25 \%)$. \\
\hline 8.10 .1990 & The UKP joins the ERM with the wide band $( \pm 6 \%)$. \\
\hline 6.4 .1992 & The ESC joins the ERM with the wide band $( \pm 6 \%)$. \\
\hline 19.4.1992 & $\begin{array}{l}\text { Realignment (BFR }+3.5 \%, \mathrm{DKR}+3.5 \%, \mathrm{DM}+3.5 \%, \mathrm{ESC}+3.5 \%, \mathrm{FF}+3.5 \% \text {, } \\
\mathrm{IRL}+3.5 \%, \mathrm{HFL}+3.5 \%, \mathrm{LIT}-3.5 \%, \mathrm{PTA}+3.5 \%, \mathrm{UKP}+3.5 \%)\end{array}$ \\
\hline 17.9.1992 & $\begin{array}{l}\text { The UKP and the LIT suspend their participation in the ERM. Realignment } \\
(\text { PTA }-5 \%) \text {. }\end{array}$ \\
\hline 23.11.1992 & Realignment (ESC $-6 \%$, PTA -6\%). \\
\hline 1.2.1993 & Realignment (IRL $-10 \%)$. \\
\hline 14.5.1993 & Realignment (ESC $-6.5 \%$, PTA $-8 \%$ ). \\
\hline 2.8 .1993 & $\begin{array}{l}\text { The ERM fluctuation bands are widened to } \pm 15 \% \text {, except for the DM and the } \\
\text { HFL. }\end{array}$ \\
\hline 9.1 .1995 & The ATS joins the ERM with the new wide band $( \pm 15 \%)$. \\
\hline 6.3 .1995 & Realignment (ESC -3.5\%, PTA -7\%). \\
\hline 14.10.1996 & The FIM joins the ERM with the new wide band $( \pm 15 \%)$. \\
\hline 25.11.1996 & The LIT re-joins the ERM with the new wide band $( \pm 15 \%)$. \\
\hline 16.3 .1998 & $\begin{array}{l}\text { Realignment (IRL }+3 \%) \text {. The GDR joins the ERM with the new wide band } \\
( \pm 15 \%) \text {. }\end{array}$ \\
\hline
\end{tabular}

Note: ATS, BFR, DKR, DM, GDR, ESC, FF, FIM, HFL, IRL, LIT, PTA and UKP denote the Austrian schilling, the Belgian franc, the Danish krone, the Deutschmark, the Greek drachma, the Portuguese escudo, the French franc, the Finnish markka, the Dutch guilder, the Irish pound, the Italian lira, the Spanish peseta and the Pound sterling, respectively. 
With the beginning of EMU, the former ERM was replaced by a new ERM-II. Under this mechanism, the four member states that did not introduce the euro at the time were given the chance to prepare themselves for full incorporation into the euro area $^{4}$. Denmark and Greece took advantage of this option from 1 January 1999, while Sweden and the United Kingdom stayed outside. Central and intervention rates were all defined in terms of the euro. A fluctuation margin of $\pm 2.25 \%$ was set for the Danish krone and a standard margin of $\pm 15 \%$ was agreed on the Greek drachma. The objective of ERM-II has been to ensure exchange-rate stability between the euro area and the European Union (EU) members who have not introduced the single currency, adding another element in the process to European integration.

On 19 June 2000, the EU Council, having assessed that Greece fulfilled the requirements of the Treaty, approved its accession to the euro area as a twelfth member from 1 January 2001. On the same day, the Council also decided that the conversion rate between the GRD and the euro should be equal to the dracma's central rate in the ERM-II. The convergence of the GRD towards its central rate was facilitated by a $3.5 \%$ revaluation of its central rate on 17 January 2000.

In 2004 and 2007, ten and two new Central and Eastern European Countries (CEECs) became EU member states. Although this did not imply immediate membership in EMU, after a two-year derogation period, their convergence has been evaluated on the basis of the Maastricht Treaty. But, in contrast to the past experiences of United Kingdom and Denmark, the CEECs are not granted with opt-out clauses in joining the EMU. In other words, the way toward the adoption of the euro is a nonreturn one for these new members.

Among the four convergence criteria (i.e., price stability, sustainable fiscal position, exchange rate stability and low interest rates) that will be used in evaluating the catching-up process of these economies, the exchange rate stability is perhaps the most striking one, given the crucial role that exchange regime plays in determining macroeconomic stability and investment climate (see ECOFIN, 2000).

When joining the EU, the currencies of the CEECs exhibited a rather heterogeneous pattern in their exchange rate movements against the euro. Given that the assessment of exchange rate stability includes as a mandatory the participation for at

3 The fluctuation band for the Italian lira was narrowed to \pm 2.25 at the beginning of 1990. This was done without changing the central parity. 
least two years in the ERM-II, most of the CEECs were expected to join it. Indeed, over the past years the euro has increasingly gained importance as the main reference currency in both the pegged and managed regimes prevailing in the CEECs and some have adopted de facto pegged with the euro (see Ledesma-Rodríguez et. al., 2008).

On 27 June 2004, at the request of the Lithuanian authorities, the Estonian kroon, the Lithuanian litas and the Slovenian tolar were included in the ERM-II. Later, on 29 April 2005, the Cyprus pound, the Latvian lats and the Maltese lira also joined the ERM II. Finally, on 25 November 2005, the Slovak koruna joined the ERM-II, In all cases, the standard fluctuation band of $\pm 15 \%$ around the central rate was set. Nevertheless, it was accepted that Estonia and Lithuania entered the mechanism with their existing currency board pegged to the euro, while the Lathvian authorities declared that they unilaterally maintain the exchange rate of the lats at the central rate against the euro with a fluctuation band of $\pm 1 \%$ and the Maltese authorities declared that they unilaterally maintain the exchange rate of the Maltese lira at the central rate against the euro.

After fulfilling the requirements of the Treaty, Slovenia introduced the European single currency on 1 January 2007, being the13th member of the euro area and the first of the new Member States to join EMU. Cyprus and Malta introduced the euro on 1 January 2008, while the Slovak Republic will do so on 1 January 2009. Therefore, in 2009 the number of EU Member States that use the single European currency will be increased to $16^{5}$.

The Slovak koruna was relatively volatile vis-à-vis during 2006. Between April and July 2006, the Slovak currency came temporarily under downward pressure and, for some time, traded slightly below its ERM II central rate. From mid-2006, it appreciated significantly, reflecting strong underlying economic fundamentals, and its central rate was revalued by $8.5 \%$ on 19 March 2007. Finally, at the request of the Slovak authorities, the central rate of the Slovak koruna was revalued by 17.65 per-

4 Participation in the ERM-II was voluntary, but it was a prerequisite for being a part of the euro at a later stage.

5 Three European microstates (Vatican City, Monaco, and San Marino), although not EU members, have adopted the euro due to currency unions with member states. Andorra, Montenegro, Kosovo and the Sovereign Base Areas Akrotiri and Dhekelia have also adopted the euro unilaterally, while not being EU members either. It is interesting to note that the Sovereign Base Areas Akrotiri and Dhekelia, which are part of the United Kingdom (but are 
cent on 28 May 2008, 21 days after the publication of the ECB Convergence Report 2008 recommending Slovakia's euro entry. Such revaluation was designed to help tackle inflation and improve its conversion rate to the euro.

Table 2. Main realignments and changes in the ERM-II (1999-2008)

\begin{tabular}{|l|l|}
\hline 1.1 .1999 & $\begin{array}{l}\text { ERM-II starts with DKR and GDR. The DKR chose a narrow band }( \pm 2.25 \% \text { fluc- } \\
\text { tuation }) \text { and the GDR the standard band }( \pm 15 \% \text { fluctuation }) .\end{array}$ \\
\hline 17.1 .2000 & Realignment (GDR $+3.5 \%)$. \\
\hline 1.1 .2001 & GDR leaves the ERM-II as Greece become a member of EMU \\
\hline 28.6 .2004 & EEK, LTL and SIT join the ERM with the standard band $( \pm 15 \%)$. \\
\hline 2.5 .2005 & CYP, LVL and MTL join the ERM with the standard band $( \pm 15 \%)$. \\
\hline 28.11 .2005 & SKK joins the ERM with the standard band $( \pm 15 \%)$. \\
\hline 1.1 .2007 & SIT leaves the ERM-II as Slonevia become a member of EMU \\
\hline 19.3 .2007 & Realignment (SKK $+8.5 \%)$. \\
\hline 1.1 .2008 & CYP and MTL leave the ERM-II as Cyprus and Malta become members of EMU. \\
\hline 29.5 .2008 & Realignment (SKK $+17.65 \%)$. \\
\hline
\end{tabular}

Note: CYP, DKR, GDR, EEK, LTL, LVL, MTL, SIT and SKK denote the Cyprus pound, the Danish krone, the Greek drachma, the Estonian kroon, the Lithuanian litas, the Latvian lats, the Maltese lira, the Slovenian tolar and the Slovak koruna, respectively.

One of the main arguments in support of the original ERM was that it facilitated the necessary process of disinflation and that it raised the costs of inflation by forcing its associates to good practices. The aim was to provide discipline to macroeconomic policies that would ensure that fiscal deficits would not be compounded by monetary expansions. In these matters, Germany emerged almost naturally as the anchor for exchange rate and inflation expectations. In fact, the ERM could be seen as an institutional arrangement which has enabled the member countries to borrow the reputation of the Bundesbank by pegging their exchange rates to the Deutschmark. In this way, weaker currencies achieved a greater degree of credibility due to the existence of reputation effects within the ERM (i.e., EU member states with histories of high inflation used the EMS as a way of importing the Bundesbank's anti-inflationary credibility). As for the ERM-II, it is expected to play a stabilizing role in CEEC's economies, contributing to get exchange rate steadiness and disciplining national authorities to pursue consistent macroeconomic policies. 


\section{CRedibility InDicAtors}

In this section we present the five approaches that have been used in the empirical literature reviewed to assess the degree of credibility of several currencies that participated in the ERM. Some of the indicators have been widely employed, while others, like the marginal credibility or the conditional elasticity, have received less attention.

\section{III.1. Svensson's simple test}

Svensson (1991) presented a simple test to study the credibility of a target zone exchange rate regime with fluctuation bands. There are two traditional versions of this test. In the first one, it is assumed that there is no arbitrage, while in the second version uncovered interest parity (UIP) is assumed to hold. To compare this indicator with the one based on the drift-adjustment method (see subsection II.2), a more recent variant of the former is usually estimated.

Given that the log of the exchange rate $s_{t}$ can be expressed as $s_{t} \int x_{t}+c_{t}$, where $x_{t}$ is the deviation of the $\log$ exchange rate from the $\log$ central parity $c_{t}$, the expected rate of currency depreciation within the band from time $t$ to $t+t$ is bounded by:

$$
\left(\underline{x}_{t}-x_{t}\right) / \tau \leq\left(E_{t}\left[\Delta x_{t+\tau}\right] / \tau \leq\left(\bar{x}_{t}-x_{t}\right) / \tau\right.
$$

where $\underline{x}_{t}$ and $\bar{x}_{t}$ are the lower and upper limits of the exchange rate bands, respectively, and $\tau$ is the maturity (being 3/12 for a 3-month maturity).

Taking into account the UIP hypothesis:

$$
i_{t}-i_{t}^{*}=E_{t}\left[\Delta \mathrm{s}_{t+\tau}\right] / \tau
$$

where $i_{t}$ and $i_{t}^{*}$ are the domestic and the foreign interest rate, respectively.

Separating the two elements of the exchange rate (i.e., the central parity and the exchange rate within the band), equation (2) can be rewritten as:

$$
i_{t}-i_{t}^{*}=E_{t}\left[\Delta x_{t+\tau}\right] / \tau+E_{t}\left[\Delta c_{t+\tau}\right] / \tau
$$

The expected variation rate in the exchange rate can be separated into two com- 
ponents: the expected rate of depreciation within the band and the expected rate of realignment of the central parity.

Combining equations (1) and (3), the expected rate of realignment is bounded according to:

$$
i_{t}-i_{t}^{*}-\left(\bar{x}_{t}-x_{t}\right) / \tau \leq\left(E_{t}\left[\Delta c_{t+\tau}\right] / \tau \leq i_{t}-i_{t}^{*}-\left(\underline{x}_{t}-x_{t}\right) / \tau\right.
$$

To facilitate the comparison with the drift-adjustment method, LedesmaRodríguez et al. (1999b, 1999c, 2000, 2005) calculate a 100\% confidence interval for the expected rate of realignment of the exchange rate under study vis-à-vis the German mark.

This recent version of Svensson's simple test has been criticised because it only takes into account the possibility of realignments in the limits of the band, thus placing an excessive weight on credibility. This is one of the reasons why the results obtained with this test might not be completely accurate.

\section{III.2. The drift-adjustment method}

This method, originally proposed by Bertola and Svensson (1993), computes an econometric estimate of the expectations of economic agents regarding the realignment in the ERM. These realignment expectations constitute an inverse measure of credibility. The drift-adjustment method assumes UIP to hold using the modified expression (3).

Moreover, if $\mathrm{p}_{\mathrm{t}}^{\tau}$ denotes the probability at time $\mathrm{t}$ of a realignment during the period from $\mathrm{t}$ to $\mathrm{t}+\mathrm{t}$, it follows that:

$$
E_{t}\left[\Delta x_{t+\tau}\right]=\left(1-p_{t}^{\tau}\right) E_{t}\left[\Delta x_{t+\tau} / n r\right]+p_{t}^{\tau} E_{t}\left[\Delta x_{t+\tau} / r\right]
$$

where the expectation terms on the right-hand side are sensitive to the absence of realignment $(n r)$ or to the presence of realignment $(r)$.

If $\mathrm{g}_{\mathrm{t}}$ denotes the expected rate of devaluation, then:

$$
g_{t}^{\tau}=E_{t}\left[\Delta c_{t+\tau}\right] / \tau+\frac{p_{t}^{\tau}}{\tau}\left\{E_{t}\left[\Delta x_{t+\tau} / r\right]-E_{t} E_{t}\left[\Delta x_{t+\tau} / n r\right]\right\}
$$


where the first term on the right-hand side is the expected rate of realignment, and the second term is the expected rate of depreciation within the band when a realignment takes place.

Combining (3) and (5), and using (6), we obtain:

$$
g_{t}^{\tau}=i_{t}-i_{t}^{*}-E_{t}\left[\Delta x_{t+\tau} / n r\right] / \tau
$$

This procedure implies estimating the expected rate of depreciation within the band [the last term on the right-hand side of equation (7)], and then computing the expected rate of devaluation $\mathrm{g}_{\mathrm{t}}{ }_{\mathrm{t}}$. Once $\mathrm{g}_{\mathrm{t}}^{\tau}$ is estimated, the corresponding 90 or 95 percent confidence intervals can be calculated. These intervals can be directly compared with those of the more recent version of Svensson's simple test ${ }^{6}$.

To compute the expected devaluation rate using equation (7), Ledesma-Rodríguez et al. (1999b, 1999c, 2000, 2005) estimate the expected rate of depreciation within the band. Following Svensson (1993), they consider the linear regression

$$
\frac{x_{t+\tau}-x_{t}}{\tau}=\sum_{j} \alpha_{j} d_{j}+\beta_{1} x_{t}+\beta_{2} i_{2}+\beta_{3} i_{t}+\varepsilon_{t+\tau}
$$

where $x_{t+\tau}$ and $x_{t}$ are the exchange rate (log) deviations from the central parity during the period $t+\tau$ and $t$, respectively, and where $i_{t}$ and $i_{t}^{*}$ are the domestic and German three-month interest rates, respectively. The variables $d_{j}$ denote the dummies for the subperiods between the realignments and the widening of the bands.

outside of the EU and under military jurisdiction,) became the first part of British sovereign territory to adopt the euro when Cyprus jointed EMU in 1 January 2008.

${ }^{6}$ When considering the practical implementation of the drift-adjustment method, the empirical studies that have computed this measure have used different econometric specifications for the expected rate of depreciation within the band. Lindberg et al. (1993), Svensson (1993), and Rose and Svensson (1994) have estimated a linear regression model where the exchange rate in $t+t$ depends on its value in moment $\mathrm{t}$ (and, in some cases, lagged exchange rates) and on the interest rate differential. On the other hand, Bertola and Svens- 
Svensson (1993) eliminated from the sample the 65 observations corresponding to the three months before a realignment took place, given that he used $\tau=3$ months. Given the important reduction in the number of observations implied by this strategy, equation (8) estimates the whole sample ${ }^{7}$. In this way, Ledesma-Rodríguez et al. (1999b, 1999c, 2000, 2005) estimated the expected depreciation rate within the band, including possible jumps in each realignment. Therefore, they obtained the expected rate of realignment, but not the expected devaluation rate $g_{t}^{\tau}$ (which, in addition, includes the expected jump in the exchange rate within the band of the realignments).

Following a «general-to-specific» modelling methodology [see, e. g., Hendry (1995)], equation (8) was continuously simplified and re-parametrised until a parsimonious representation of the data generation process was arrived at.

The drift-adjustment method has been used to calculate the 90 percent confidence intervals for the expected rate of devaluation. To that end, Ledesma-Rodríguez et al. (1999b, 1999c, 2000, 2005) estimated the expected rate of depreciation within the band using a linear regression model where the exchange rate and the domestic and foreign interest rates are taken as explanatory variables.

The drift-adjustment method has been widely criticized. In particular, it has been pointed out that the selection of the explanatory variables is ad hoc, without an appropriate theoretical framework. Furthermore, the fluctuating nature of the exchange rate may generate difficulties in the estimation of its expected rate of variation. These problems depend on its position within the band. Thus, it is important to be careful when interpreting the results obtained from this method.

\section{III.3. Models of discrete choice}

These models attempt to estimate the probability of realignment by means of econometric techniques. To that end, some explanatory variables to compute that probability are usually considered, assuming normal or logistic distributions. Among the explanatory variables, the interest rate differential, the inflation differential, the current account balance, and the unemployment rate are the variables considered most often, with estimations that use monthly or quarterly data.

son (1993) consider $x_{t}$ as the only explanatory variable, assuming a mean-reverting model 
Edin and Vredin (1993) employed a two-step procedure, suggested by Heckman (1976), to calculate both the probability and the expected size of a devaluation. In the first step of the procedure, the probability of devaluation occurring at time $t+1$, based on information available at time $t$, was estimated. In the second step, the unconditional expectation of the rate of devaluation in period $t$ was obtained.

Instead of estimating the probability of realignment proposed by Edin and Vredin (1993), Ledesma-Rodríguez et al. (1999b, 1999c, 2000) estimated the value of that probability using the same daily data employed in all the other credibility indicators analysed.

They estimated a logit model based on the following equation:

$$
P_{t}=P\left(y_{t}=1\right)=\Phi\left(z_{t}^{\prime} \delta\right)=-\frac{e^{z_{t}^{\prime} \delta}}{1+\frac{e^{z_{t}^{\prime}} \delta}{} \delta} ; \quad z_{t}^{\prime} \delta=\delta_{1}+\delta_{2} z_{1 t}
$$

where $\Phi(\cdot)$ is the logistic distribution function $(\mathrm{F}(1)$ is the probability that a normally distributed random variable with zero mean and unit variance does not exceed $\lambda, \mathrm{z}_{1 \mathrm{t}}$ denotes an explanatory variable, and $\mathrm{P}\left(\mathrm{y}_{\mathrm{t}}=0\right)=1-\mathrm{P}_{\mathrm{t}}$. The parameters in equation (9) are estimated by maximising the logarithm of the likelihood function with respect to individual observations:

$$
\log L=\sum_{t=1} y_{t} \log \Phi\left(z_{t}^{\prime} \delta\right)+\sum_{t=1}\left(1-y_{t}\right) \log \left[1-\Phi\left(z_{t}^{\prime} \delta\right)\right]
$$

The drift-adjustment method estimates the $90 \%$ confidence interval (calculated in section II.2). If both limits of the interval were simultaneously greater or lesser than zero, the agents would have expected realignments with $90 \%$ confidence. Assuming that when $\mathrm{y}_{\mathrm{t}}=0$ there is no credibility and that when $\mathrm{y}_{\mathrm{t}}=1$ there is credibility, we use the drift-adjustment method to design the logit model. In other words, when $y_{t}=0$ the limits of the confidence interval for the expected rate of realignment are simultaneously greater or lower than zero. When $\mathrm{y}_{\mathrm{t}}=1$ this does not occur ${ }^{8}$. This strategy allows

for the exchange rate within the band, as in Ayuso et al. (1994) and in Gómez-Puig and Montalvo (1997).

7 Gómez-Puig and Montalvo (1997) follow a similar approach. 
knowledge of the probability that agents assign to the credibility of the exchange rate regime at each moment of time.

Ledesma-Rodríguez et al. (1999b, 1999c, 2000) used different approaches to estimate the probability that national commitments towards the ERM were credible, defining $\mathrm{z}_{\mathrm{t}}$ as the explanatory variable: either the exchange rate, or the distance to the upper fluctuation band, or the distance to the central parity, or the interest rate differential.

\section{III.4. Marginal credibility}

This measure, proposed by Weber (1991a), focuses on the ability of policy announcements to influence the public's expectations, and calculates the impact of official declarations on exchange rates. It may be thought of as the weight placed on the announcement when people form their expectations. This credibility measure is equal to one if the policy-maker always makes fully credible announcements, and tends to zero as the announcements become less credible. In this case, the changes in the ERM central parity are the announcements.

Marginal credibility $\left(\alpha_{t}\right)$ is defined as:

$$
s_{t}-\mathrm{E}_{t-1}\left[s_{t}\right]=\gamma+\alpha_{t}\left[c_{t}-\mathrm{E}_{t-1}\left[s_{t}\right]\right]+u_{t}
$$

where the expectations operator is conditional to the information available in $t-1$, and where the random disturbance $u_{t}$ is normal with zero mean and constant variance.

A model of the public's expectation forming process is required in order to estimate $a_{t}$. By applying the Kalman filter, $a_{t}$ can be estimated, obtaining a different value of $\alpha_{t}$ for each moment in the sample period, which allows the study of credibility through its evolution over time.

Before estimating $\alpha_{t}$, Ledesma-Rodríguez et al. (1999b, 1999c, 2000) obtained the expectations on the exchange rate, using the best ARIMA model for each exchange rate. To calculate marginal credibility, they used the Kalman filter to examine the dynamic behaviour of the estimated $\alpha_{t}$ during the sample period ${ }^{9}$.

${ }^{8}$ Note that this measure, when formulated in this manner, assigns credibility to any period when neither the lower bound of the confidence interval is positive nor the upper bound is negative. 
The model estimated is the following:

$$
\begin{array}{cc}
y_{t}=w_{t} \beta_{t}+\varepsilon_{t} ; & \varepsilon_{t} \sim N\left(0, \sigma^{2} h_{t}\right) \\
\beta_{t}=T \beta_{t-1}+\eta_{t} ; & \eta_{t} \sim N\left(0, \sigma^{2} Q_{t}\right)
\end{array}
$$

where $\mathrm{y}_{\mathrm{t}}$ is a vector of differences $s_{t}-E_{t-1}\left(s_{t}\right)$, is a row vector made of ones and differences $c_{t}-E_{t-1}\left(s_{t}\right)$. Equation (13) is called the transition equation (it describes the evolution of a set of state variables), whereas equation (12) is the measurement equation (it describes how the data actually observed is generated from the state variables). $\beta_{t}$ is the state vector that follows a random walk and $T$ is an identity $2 \times 2$ matrix. The initial conditions are established by $\beta_{0} \sim N\left(\beta_{0}, P_{0}\right)$, where $P_{0}$ is a variance-covariance matrix for the initial conditions. Finally, $h_{t}$ is the variance of the errors in the measurement equation and $Q_{t}$ is the variance-covariance matrix for the errors in the transition equation.

The Kalman filter is a recursive method that computes the optimal estimate of the state variables in period $t$, based on information available in $t$. For each period, Ledesma et al. (1999b, 1999c, 2000) apply a conditional maximum likelihood to the information available for that period. The logarithm of the likelihood function is defined as follows:

$$
\log L=-\frac{T}{2} \log 2 \pi-\frac{1}{2} \sum_{t=1}^{T} \log \sigma^{2}-\frac{1}{2} \sum_{t=1}^{T} \log f_{t}-\frac{1}{2}-\sum_{t=1}^{T} \xi_{t}^{\prime} f_{t} \xi_{t}
$$

where $\sigma^{2}$ is computed from the recursive residuals $f_{t}=w_{t}^{\prime} P_{t / t-1} w_{t}+h_{t}$, is a scalar and $\xi_{t}^{\prime}=y_{t}-E_{t-1}\left[y_{t}\right]$.

The use of an econometric technique that allows for changes in the values of the parameters over time may be appropriate for the study of credibility in a target zone: stabilising interventions by the central banks, realignments, and speculative movements by private agents modify the parameters of the process within the period being studied. In fact, this possibility was pointed out by Weber (1991a, 1991b), before the monetary turmoil of September 1992, and later on by Darvas (1998). 


\section{III.5. Conditional volatility}

In a similar strategy to the one employed by Malliaropulos (1995), a study of credibility is carried out in Ledesma-Rodríguez et al. (1999a) fixing their attention on the evolution of daily exchange rate. They propose a conditional elasticity index to measure the degree of integration of the EMS as perceived by the economic agents, building on the estimation of the conditional variances and covariances and the risk premia of the Spanish peseta/Dutch guilder and the German mark/Dutch guilder ${ }^{10}$ from the entrance of the peseta in the ERM on the $19^{\text {th }}$ of June 1989 , until the $8^{\text {th }}$ of May 1997. In particular, if agents expect that any change in the parity of currency B with respect to currency A will be replicated in an exact proportional variation for $\mathrm{C}$ with respect to $\mathrm{A}$, then those agents believe in a system of fixed exchange rates among the currencies considered. Conversely, when the anticipated changes do not coincide, the weakening of one currency and the relative strengthening of the other will be expected.

Ledesma-Rodríguez et al. (2001) propose a credibility indicator based also on Malliaropulos' conditional volatility, i.e., the constant correlation of the coefficients between each pair of exchange rates. They showed the presence of non-linearities in several core ERM exchange rates with respect to the Deutschmark through the significance of GARCH effects on these variables. Additional evidence on the degree of credibility of the EMS is provided, employing this indicator to the study of the French franc, the Danish krone, the Belgian franc, and the Dutch guilder, all with respect to the German mark, using the conditional approach strategy that Malliaropulos (1995) applied before to the study of some ERM exchange rates with respect to the US dollar ${ }^{11}$.

9 The Kalman filter is an updating estimation method which bases the regression estimates for each time period on the last period's estimates plus the data for the current time period (i.e., it bases estimates on data up to and including the current period).

10 This technique requires a reference currency in order to study the proportionality in the movements of two currencies. The chosen reference was the Dutch guilder, as this cur- 


\section{EMPIRICAL RESUlts}

The credibility indicators presented in the previous section were applied in two studies of the Spanish peseta (Ledesma-Rodríguez et al., 1999a; 1999b) to daily exchange rate and three-month interest rate data, obtained from the Bank of Spain, covering the period from the $19^{\text {th }}$ of June 1989, the date the peseta joined the EMS, to the $8^{\text {th }}$ of May 1997. Figure $1 \mathrm{~h}$ shows the evolution of the peseta in the ERM.

In Ledesma-Rodríguez et al. (1999a) the conditional elasticity index for the Spanish peseta/German mark exchange rate showed, on one hand, a lower level of confidence in the ERM after the peseta joined the EMS, and on the other, a worsening in the credibility level at the time of the entrance of new currencies into the ERM. The subsequent periods that exhibited the lowest levels of credibility were September and November of 1992 (devaluations of the peseta and the exit of the British pound and the Italian lira), and the first months of 1995, which led to the last devaluation of the peseta in March of that year. The non-detection of some crisis periods, like the widening of the fluctuation bands on the $2^{\text {nd }}$ of August, 1993, was acknowledged to be the main fault of the conditional elasticity index. Furthermore, the conditional elasticity measure was found to be too sensitive, hindering the deduction of clear inferences about the evolution of the degree of credibility of the Spanish peseta with respect to the Deutschmark.

Ledesma-Rodríguez et al. (2001) apply the conditional volatility measure, suggested by Malliaropulos (1995), to four core ERM currencies using daily spot exchange rates gathered between 1 January 1978 and 8 May 1997. Figures 1a (Belgian franc), 1b (Danish krone), 1f (French franc), and 1e (Dutch guilder), show the evolution of the exchange rates. The sample period had also been divided in two subperiods: before the enlargement of the bands on 2 August 1993, and after that date, from $\pm 2.25 \%$ to $\pm 15 \%$. The results obtained in this study indicate that, in general, economic agents did not perceived a complete integration of the core currencies of the ERM, which is true for the greatest part of the history of the EMS. Nevertheless, the conditional correlation index points to a greater degree of credibility after the widening of the fluctuation bands.

The indicators used in Ledesma et al. (1999b), probability of devaluation, marginal credibility and the one based on the drift-adjustment method (DAM), suggest, generally, though not for all the measures, that the entrance of the peseta in the ERM also led to a lower level of confidence in the system. Moreover, the periods in the EMS history with the greatest fall in credibility were the same ones found in Ledes- 
ma et al. (1999a), i.e., September-November of 1992 and January-March of 1995, adding now the period from May (the third devaluation of the peseta) to July of 1993 (just before the broadening of the fluctuation bands in August).

Ledesma et al. (1999b) present a comparison study among indicators in terms of their predictive ability of the main crisis episodes. To that end, for each indicator the changes of the first and second order moments prior to the three main events of the sample period are calculated ${ }^{12}$. They chose the fifteen days prior to 14 September 1992 (the worst moment of the European monetary turmoil), 2 August 1993 (the broadening of the fluctuation bands), and 6 March 1995 (the last devaluation of the peseta and of the Portuguese escudo). By calculating the mean and the standard deviation for the whole period, as well as for the four subperiods, they measured the percentage differences between the values for each one of these subperiods and the corresponding values for the complete period. The comparison of the measures used suggested that the marginal credibility index (calculating the exchange rate expectations as an $\operatorname{AR}(1)$ process) was the best measure for capturing the main events, i.e., to catch the volatility of the exchange rate over time. MAD seemed to be a good indicator for capturing changes in volatility.

Ledesma-Rodríguez et al. (1999c) examine the credibility of the Portuguese escudo/German mark exchange rate, from the moment that the escudo joined the EMS on 6 April 1992 until 8 May 1997. Figure 1c shows the evolution of the escudo in the ERM. Several indicators found a worsening of credibility around September 1992 (devaluation of the peseta and the exit of the British pound and the Italian lira from the EMS), in November 1992 (devaluation of the escudo and second devaluation of the peseta), just before the widening of the fluctuation bands in August 1993, and in the first months of 1995 (leading to the last devaluation of the escudo in March 1995).

The study showed that the devaluations of the escudo were forced more by external causes (difficulties for other ERM currencies and excessive volatility in international financial markets) than by domestic ones. In fact, the escudo was usually far away from the bands. Thus, the three devaluations of the escudo were closely associated to devaluations of the peseta when the latter was situated near its fluctuation limits. A case in point could be observed in the realignment of March 1995, when the escudo was around its central parity and at a considerable distance from the bands.

rency exhibited a similar behaviour to the German mark.

11 Malliaropulos (1995) did not find evidence that the fluctuations of the US dollar were 
Ledesma-Rodríguez et al. (2000) analyse the daily spot exchange rate credibility of the Irish pound vis-à-vis the Deutschmark, from 21 November 1983 to 17 February 1997. Figure 1f shows the evolution of the Irish pound in the ERM. They found credibility gains after the realignments of the Irish pound on 4 August 1986, on 12 January 1987, and on 1 February 1993, after the broadening of the fluctuation bands to \pm 15 per cent on 2 August 1993, and around the devaluations of the peseta and the escudo on 6 March 1995. Conversely, they detect some occasional reductions in credibility, notably before the monetary turmoil of September 1992 and just after the Italian lira rejoined the ERM on 25 November 1996.

The results obtained by Ledesma-Rodríguez et al. (2000) suggest that the August 1986 realignment, in response to the weakness of the pound sterling (which was outside the EMS at the time), helped credibility by making the exchange rate sustainable, opening up a period of stability for the Irish pound that lasted until 1992. Indeed, in 1987 the Central Bank of Ireland adopted a strategy based on a rigid peg with respect to the German mark and total commitment to ERM parities (Walsh, 1993). This is very noticeable after 1987 due to two important developments within the EMS: the German unification and the removal of capital controls in some countries. However, when the British pound sterling left the ERM in September 1992 and depreciated against the Deutschmark, Irish exchange rate policy exhibited a lack of credibility and speculative pressures forced a new realignment of the Irish pound in February 1993.

With the broadening of the ERM bands in August 1993, the Central Bank of Ireland obtained a greater degree of flexibility in determining exchange rate policy, allowing the monetary authorities to easily accommodate the sharp depreciation of the pound sterling relative to the German mark, registered at the end of 1994 and early in 1995, in contrast with the 1992 episode (Walsh, 1995), when this did not occur. Nevertheless, when the Italian lira re-entered the EMS in November 1996, leaving the British pound out of the ERM, the scenario of Ireland satisfying the Maastricht criteria but the United Kingdom opting out of the Economic and Monetary Union (EMU) temporarily reduced the credibility of the Irish pound.

The comparison of the indicators used in the study of the Irish pound (LedesmaRodríguez et al., 2000) showed again, as in Ledesma-Rodríguez et al. (1999b), that the marginal credibility measure was the best (overall, and mainly in terms of the standard deviation) for capturing the main events of the sample period. In this case, the expected exchange rates were calculated using a random walk model with a drift. Therefore, the use of an econometric technique that allows the parameters to change with time seemed to be appropriate for the study of credibility in a target zone. 
Hochreiter and Tavlas (2004) performed a simple credibility test, based on Svensson (1991) for Austria and Greece using data that covers the 1970-1999 and the 19932000 perriod, respectively. Their results for Austria suggest that it took until 1989 for long-term devaluation risk to be eliminated and that that the collapse of the government in 1995 (because of disagreements regarding fiscal consolidation) did not affect credibility. As far as Greece is concerned, they found evidence of a devaluation risk; interest rate remained above the rate-of-return band until the final quarter of 1999

Ledesma-Rodríguez et al. (2005) carry out a credibility analysis of the entire EMS history. To that end, eight currencies (five corresponding to countries exhibiting good fundamentals, and three pertaining to peripheral member states) vis-à-vis the Deutschmark are studied. Figures 1a to $1 \mathrm{~h}$ show the evolution of the exchange rates studied. The paper presents a balanced view of the ERM, identifying what is common to all and what is specific to each country during the different crises periods.

The main focus of Ledesma-Rodríguez et al. (2005) is on the comparison of the prediction quality (in detecting exchange rate crises) of six credibility indicators: one based on the drift-adjustment method (DAM), another on the marginal credibility, and the four crisis probability indices based on the exchange rate, on the interest rate differential, and on the distances to the central parity and to the upper band. Three alternative approaches are used for comparison. The first one, as already explained above, evaluates the indicators in terms of their mean and variance (Ledesma-Rodríguez et al. , 1999b; 2000). Marginal credibility seems to be the most accurate measure for predicting the selected events (i.e., the realignments of each exchange rate and the broadening of the fluctuation bands). Again, the expected exchange rates were calculated using a random walk model with a drift.

The other two approximations explore new roads to assess the ability of the indicators to identify the main periods of speculative attacks and realignments in the ERM. The second approach considers that economic agents utilize some procedure to extract signals from the indicators in order to continually re-evaluate the exchange rate commitments of the EMS. Ledesma-Rodríguez et al. (2005) postulate that market participants use moving averages (MA), the simplest and most common trading rule, i.e., the signal-extraction procedure used by market analysts to infer, from their behaviour

a significant influence on the stability of the EMS.

12 The same comparison of indicators appears in Ledesma-Rodríguez et al. (2000), for the Irish pound, and in Ledesma-Rodríguez et al. (2003), for eight currencies of the ERM. 
in the past, the likely course of future movements in the credibility indicators ${ }^{13}$. Once more, the marginal credibility measure clearly outperforms the rest of the indices ${ }^{14}$, regardless of what length of MA is considered for the extraction of signals, except for the case of the Irish pound, where the DAM index yields the highest success ratio. The second best indicator is the probability of realignment based on the distance of the exchange rate to the central parity, except for the Belgian franc, where the DAM indicator is ranked in second place. This result suggest the relevance of maintaining the exchange rate near the central parity in order to avoid system instability, as suggested by Bertola and Caballero (1992).

The third approach examines the prediction quality of the indicators in terms of efficiency by the application of Data Envelopment Analysis (DEA). In particular, Ledesma et al. (2005) apply an input-oriented DEA method in which they have five inputs, each one being the average error associated with the use of each one of the five MA rules that they have analysed. In four out of the five cases considered in this approach, the highest values of the efficiency parameter are those obtained for marginal credibility, the exception being the Irish pound. Moreover, for three currencies, the Belgian franc, the Danish krone and the Portuguese escudo, the marginal credibility indicator yields the maximum level of efficiency (i.e., a value of 1). These results reinforce Ledesma-Rodríguez et al. (1999b, 2000)'s previous conclusion that marginal credibility seems to be the best indicator in order to capture true signals of realignments and that it does not convey false signals. As before, the probability of realignment based on the distance of the exchange rate to the central parity appears in the second position of the ranking obtained.

Furthermore, Ledesma et al. (2005) examine the ERM-II from 1 January 1999 to 1 January 2001 for the Greek drachma and from 1 January 1999 to 30 September 2002 for the Danish krone ${ }^{15}$, studying the credibility of both exchange rates vis-à-vis the Euro.

The central bank of Denmark chose to stabilise the krone close to the central rate. In spite of this, the indicators pointed to instability in the run-up and the aftermath of the Danish rejection of the adoption of the euro on 28 September 2000. Indeed, these pressures were countered by foreign exchange interventions and key interest rate

13 Aconsiderable amount of research has given support to the view that technical trading rules can provide valuable economic signals in foreign exchange markets [see, Dooley and Shafer (1983), Taylor (1992) and Levich and Thomas (1993), among others].

14 Marginal credibility is the best measure to detect the true signals given by realign- 
changes. In fact, the central bank intervened in the markets during the month of September, purchasing foreign exchange to dampen an appreciation of the krone. The probability of realignment based on the interest rate differential detects this event more clearly from June to October of 2000, as well as in January 2001. Ledesma et al. (2005) conclude that the Danish status in the Economic and Monetary Union seems to be due to non-economic reasons, since the behaviour of its fundamentals would easily permit its admission to the euro as captured by the credibility indicators.

Ledesma-Rodríguez et al. (2005) find that the Greek drachma was perceived to enter the ERM-II on January 1999 with an undervalued central parity in order to avoid speculative attacks. In this sense, the revaluation of January 2000 brought the market exchange rate nearer to its new central parity. The marginal credibility shows a slow reduction in credibility that stops only after the realignment occurs. For their part, the Drift-Adjustment Method and the probability of devaluation detect instability only around the realignment date.

Finally, Horváth (2006) examines the daily exchange rate dynamics in selected EU new member states (Czech Republic, Poland, Romania, and Slovakia) using GARCH and TARCH models between 1999 and 2004. His results suggest that these countries tried to reduce volatility of the spot exchange rate despite their official policy of free floating and inflation targeting. However, he finds that the low credibility of exchange rate policy implied higher volatility of exchange rates when it substantially deviated from the implicit target rates for all countries.

\section{Concluding Remarks}

This paper presents an overview of research on the application of alternative measures to evaluate the credibility of the EMS up to its closing date on 30 December 1998. We show, in detail, the five approaches that have been employed to assess the degree of credibility of several of the currencies that participated in the ERM.

The results of the credibility studies surveyed are in agreement with the evolution of the EMS (see, e. g., De Grauwe, 2000). The relatively large fluctuation bands (compared to those of the Bretton Woods system) originally set in the ERM, together with relatively small and frequent realignments, helped reduce the size of speculative capital movements and stabilised the system during the 1979-1986 period. From 1987 to September 1992 the evolution of the EMS into a truly fixed exchange rate system with almost perfect capital mobility and greater convergence in economic fundamentals denoted an increasing confidence in the ERM. 
The successive crises after September 1992, which took the pound sterling and the Italian lira out of the EMS, seemed a demonstration of credibility losses in the context of policy conflicts among member states about how to face the severe recession experienced in 1992-93. Finally, after August 1993, the ERM changed its nature drastically, gaining credibility with the enlargement of the fluctuation bands to $\pm 15 \%$ (thus reducing the scope for speculative gains). As a result, speculation became a stabilising factor and the market rates converged to the fixed conversion rates, even though the world was hit by a major financial crisis during the second half of 1998 (De Grauwe et al., 1999).

Ledesma-Rodríguez et al. (1999b; 2000; 2005) compare the indicators according to their ability to detect the main events in the history of the EMS. The results suggest that, in general, marginal credibility is the best measure for capturing the true signals of realignments and to not convey false signals. This could be due to the fact that this is an indicator that recognises the changing nature of central parities, the width of the bands, and the realignment expectations in the history of the ERM. The probability of realignment based on the distance of the exchange rate to the central parity was ranked second in the comparative exercise carried out in Ledesma-Rodríguez et al. (2005). The latter may indicate how appropriate it is to keep the exchange rate close to central parity in order to avoid system instability, as suggested by Bertola and Caballero (1992).

The EMS experience suggests that such an exchange rate system can only operate within the framework of a temporary regime that is moving towards a full monetary union, since it may be too fragile as a permanent monetary regime (see, e.g., Bean, 1992; Eichengreen, 1994; 2000). Thus, after a year of successive crises, the first cooperative answer of the member states in August 1993 was to once again accept the possibility of easier (adjustable pegs) realignments and to widen the fluctuation limits of the target zone. In any case, the vehement commitment to political integration led to monetary unification through the creation, on 1 January 1999, of a new currency: the euro.

Regarding the future of the EMS, it is expected that new member states will gradually join the ERM-II. As any other fixed regime the ERM-II is expected to be «leading», strictly meaning that the design of economic policies must take into account the maintenance of the pre-committed rate. Participation in ERM II is a very important step on the road to the euro. A smooth participation in ERM II is testimony for the sustainability of the necessary convergence process prior the adoption of the euro. ERM II participation ties the exchange rate and hence acts as a «testing phase» of the irrevocably exchange rate fixation, playing a stabilizing role in CEEC's economies. 
The ERM-II could face similar problems to those experienced by the EMS during 1992-1993 (i.e., that if the prospect for a quick entry into the euro of the «out» members are weak, there could be speculative crises and a possible collapse of the arrangement). Indeed, the ERM-II must be judged in the light of the enlargement of the European Union once it is put to a test after new currencies join it, and we consider that the ERM experience revised in this paper could be of interest to current and potential ERM-II members. Indeed, reduced daily exchange rate fluctuations suggest that Croatia, Morocco, Norway, Switzerland and Tunisia could have being pegging their currencies more or less tightly to the euro. Moreover, Bosnia-Herzegovina and Morocco have currencies pegged to the euro, as well as several possessions and former colonies of EU states (French Polynesia, New Caledonia, Wallis and Futuna, Cape Verde; the Comoros and fourteen nations of Central and West Africa). Finally, Russia, Belarus, Ukraine, Algeria, Egypt or Turkey might also reconsider their exchange rate strategies, linking their currencies to the euro giving the increasing importance of their commercial and financial links with euro area.

After entry into ERM II with a credible central parity, participation in the system may yield additional credibility and hence stability. As De Grauwe and Grimaldi (2002) have argued, the probability of a currency crisis in a fixed exchange rate regime such as ERM II may be lower when participation in that regime without devaluation is a condition for entry into the EMU. This is because in that case the cost of devaluation for the government sharply increases. Since this is known to the market it is likely to affect the expectations of speculators in a positive way. In this respect the experience of the former South European EMS members can be illustrative. As is well known, these countries went through a smooth transition course into the EMU, once an entry date and a credible conversion rate for their currencies was established.

Therefore, the results obtained are of interest, not only for the European experience in the 1979-1998 period and for the ERM-II, but also for the analysis of other possible target zones that may develop in Latin America or Asia, as well as other implicit peg regimes, as argued by Reinhart and Rogoff (2002). On the one hand, those countries are small open economies (highly susceptible to exchange rate movements and, therefore, more probable to be considered by monetary authorities) and their financial markets are less developed and do not allow domestic firms to borrow in their home currency (constituting a further incentive to peg because they debt is nominated in foreign currency). On the other hand, those countries may lack the political support for the necessary but unpopular measures to defend a de iure peg, hence being more prompt to follow a de facto peg. Moreover, with de facto pegs, exchange- 
rate adjustments are less visible to the public and less costly politically than devaluation under an official peg.

The history of the EMS seems to uphold the view that, in an environment of financial deregulation and high capital flows, soft pegs and managed floats without a credible monetary policy call for intense speculative activity, since in that context there exist clear possibilities of earning windfall profits.

\section{REFERENCES}

Ayuso, J.; Pérez-Jurado, M. and Restoy, F. (1994): Is Exchange Rate Risk Higher in the ERM After the Widening of Fluctuation Bands?». Documento de Trabajo 9419, Banco de España, Madrid.

Bean, C. (1992): «Economic and Monetary Union in Europe», Journal of Economic Perspectives, Vol. 6, pp. 101-121.

Bertola, G. and R.J. Caballero (1992): «Target Zones and Realignments», American Economic Review, Vol. 82, pp. 520-536.

Bertola, G. and L.E.O. Svensson (1993): «Stochastic Devaluation Risk and the Empirical Fit of Target Zone Models», Review of Economic Studies, Vol. 60, pp. 689-712.

DARvas, Z. (1998): «Spurious Correlation in Exchange Rate Target Zone Modelling: Testing the Drift-Adjustment Method on the US Dollar, Random Walk and Chaos», CEPR Discussion Paper No. 1890.

De Grauwe, P. (2000): Economics of Monetary Union. Fourth edition. Oxford: Oxford University Press.

De Graume, P. and Grimaldi, M. (2002):»Exchange Rate Regimes and Financial Vulnerability», European Investment Bank Papers, Vol. 7, No. 2, pp. 33-48.

De Grauwe, P.; Dewachter, H. and D. Veestraeten (1999): «Explaining recent European Exchange-rate Stability», International Finance 2, pp. 1-31.

Dooley, M. P. and J. SHAFER (1983): «Analysis of short-run exchange rate behaviour: March 1973 to November 1981», in D. Bigman and T. Taya, (eds.), «Exchange rate and trade instability: Causes, consequences and remedies», Ballinger, Cambridge.

ECOFIN (2000): "Questions relating to the applicant countries' economic stability and exchange rate strategy: Conclussions», 2283rd Council meeting, Brussels, July 17 (available at http://ue.eu.int/newsroom/main.cfml).

EDIN, P.-A. and A. VREDIN (1993): «Devaluation Risk in Target Zones: Evidence from the Nordic Countries», Economic Journal, Vol. 103, pp. 161-175.

EICHENGREen, B. (1994): International Monetary Arrangements for the $21^{\text {st }}$ Century. Washington, DC, The Brookings Institution.

- (2000): «The EMS Crisis in Retrospect», Working Paper 8035, NBER Working Paper Series. 
Frankel, J. (1999): No Single Currency is Right for all Countries or at all Times, Essays in International Finance, 215, Princeton University Press.

Giavazzi, F., and L. Spaventa (1991): "The "new" EMS», in P. De Grauwe and L. Papademos (eds.), The European Monetary System in the 1990's, CEPS.

Gómez-Puig, M. and J.G. Montalvo (1997): «A New Indicator to Assess the Credibility of the EMS», European Economic Review, Vol. 41, pp. 1511-1535.

Heckman, J. (1976): »The Common Structure of Statistical Models of Truncation, Sample Selection and Limited Dependent Variables and a Simple Estimator for Such Models», Annals of Economic and Social Measurement, Vol. 5, pp. 475-492.

HeNDRY, D. F. (1995): Dynamic Econometrics (Oxford: Oxford University Press).

Hochreiter, E and TAVLAS, G. S. (2004): «On the road again: an essay on the optimal path to EMU for the new member states», Journal of Policy Modeling, Vol. 26, pp. 793-816.

Horváth, R. (2006): «Credibility of Exchange Rate Policies in Selected EU New Members: Evidence from High Frequency Data», Working Paper 2006/28, Institute for Economic Studies, Prague.

Kempa, B. and Nelles, M. (1999): «The Theory of Exchange Rate Target Zones», Journal of Economic Surveys, Vol. 13, pp. 173-210.

Krugman, P.R. (1991): «Target Zones and Exchange Rate Dynamics», Quarterly Journal of Economics, Vol. 106, pp. 669-682.

Ledesma-Rodríguez, F.; Navarro-Ibáñez, M.; Pérez-Rodríguez, J. and S. Sosvilla-Rivero (1999a): «A Study of the Credibility of the Spanish Peseta», Estudios de Economía Aplicada, No. 11, pp. 85-100.

- (1999b): «Una Aproximación a la Credibilidad de la Peseta en el Sistema Monetario Europeo», Moneda y Crédito, No. 209, pp. 195-230.

- (1999c): «Una Aproximación a la Credibilidad del Escudo en el Sistema Monetario Europeo», Economia, Vol. XXIII, pp. 69-95.

- (2000): «On the Credibility of the Irish Pound in the EMS», Economic and Social Review, Vol. 31, pp. 151-172.

- (2001): «Una nota sobre credibilidad y no linealidad», Revista Asturiana de Economía, No. 22, pp. 107-121.

- (2005): «Assessing the Credibility of a Target Zone: Evidence from the EMS», Applied Economics, Vol. 37, pp. 2265-2287.

Ledesma-Rodríguez, F.; Pérez-Rodríguez, J. and S. Sosvilla-Rivero (2008): «Detecting Implicit Exchange Regimes in Central and Eastern Europe», paper presented in the 7th INFER Workshop on International Economics, Universidad de Murcia, Murcia.

Levich, R. and L. Thomas (1993), «The significance of technical trading rule profits in the foreign exchange market: A bootstrap approach», Journal of International Money and Finance, Vol. 12, pp. 451-474.

Lindberg, H.; SöDerlind, P. and L.E.O. Svensson (1993): «Devaluation Expectations: The Swedish Krona 1985-92», Economic Journal, Vol. 103, pp. 1170-1179.

Malliaropulos, D. (1995): «Conditional Volatility of Exchange Rates and Risk Premia in the EMS», Applied Economics, Vol. 27, pp. 117-123. 
Reinhart, C.M. and V.R. Reinhart (2003): «Twin Fallacies About Exchange Rate Policy in Emerging Markets», Moneda y Crédito, No. 216, pp. 11-29.

Reinhart, C.M. and K.S. Rogoff (2002): «The Modern History of Exchange Rate Agreement: AReinterpretation», Working Paper 8963, NBER Working Paper Series.

Rose, A.K. and L.E.O. Svensson (1994): «European Exchange Rate Credibility Before the Fall», European Economic Review, Vol. 38, pp. 1185-1216.

Sosvilla-Rivero, S.; Fernández-Rodríguez, F. and Bajo-Rubio, O. (1999): «Exchange Rate Volatility in the EMS Before and After the Fall», Applied Economics Letters, Vol. 6, pp. 717-722.

Svensson, L.E.O. (1991): «The Simplest Test of Target Zone Credibility», IMF Staff Papers, Vol. 38, pp. 655-665.

- (1993): «Assessing Target Zone Credibility: Mean Reversion and Devaluation Expectations in the ERM, 1979-1992», European Economic Review, Vol. 37, pp. 763-802.

TAvlas, G. S. (2003): «The Economics of Exchange-Rate Regimes: AReview Essay», World Economy, Vol. 26, pp. 1215-1246.

TAYLOR, S. J. (1992): «Rewards available to currency future speculators: Compensation for risk or evidence of inefficient pricing?», Economic Record, Vol. 68, pp. 105-116

Van Poeck, A.; Vanneste, J. and Veiner, M. (2007): «Exchange Rate Regimes and Exchange Market Pressure in the New EU Member States», Journal of Common Market Studies, Vol. 45, pp. 459-485.

WALSH, B. (1993): «The Irish Pound and the ERM: Lessons from the September Crisis and its Aftermath», Working Paper 93/14, Centre for Economic Research, University College Dublin.

- (1995): «Irish Exchange Rate Policy Under Wide ERM Bands», Working Paper 95/15, Centre for Economic Research, University College Dublin.

Weber, A. (1991a): «EMS Credibility», Economic Policy, No. 12, pp. 58-102.

- (1991b): «Stochastic Process Switching and Intervention in Exchange Rate Target Zones: Empirical Evidence from the EMS», CEPR Discussion Paper No. 554. 
Figure 1a. BFR/DM exchange rate (including ERM intervention limits)

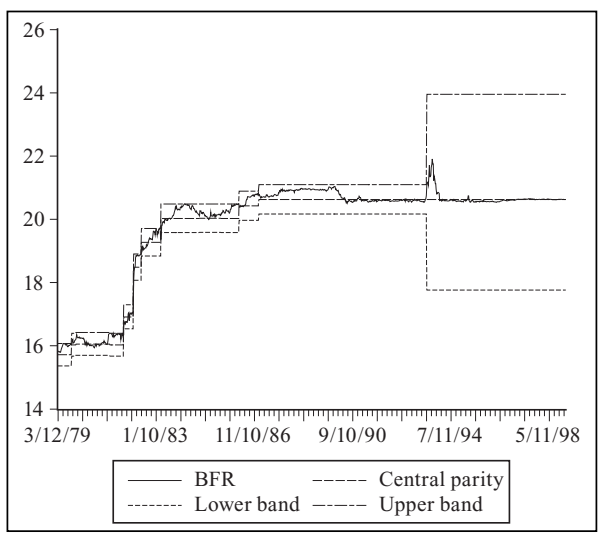

Figure 1c. ESC/DM exchange rate (including ERM intervention limits)

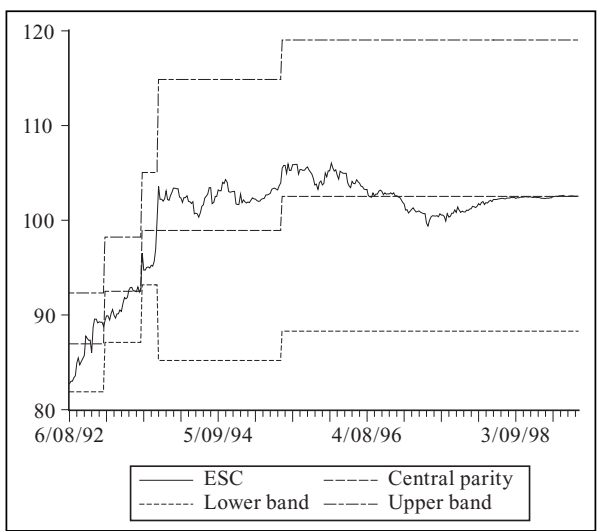

Figure 1b. DRK/DM exchange rate (including ERM intervention limits)

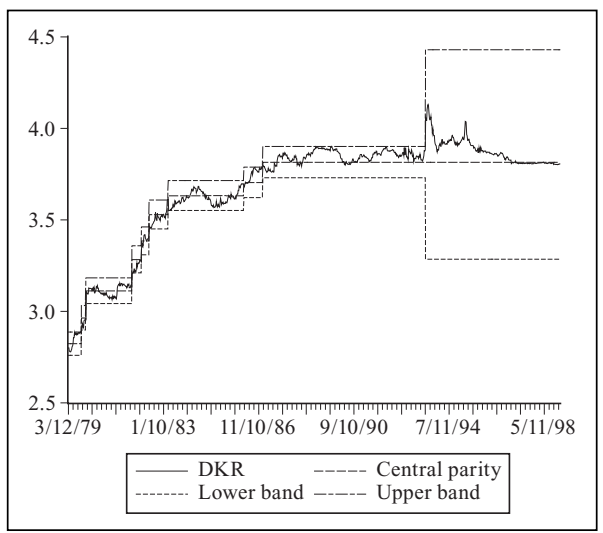

Figure 1d. FF/DM exchange rate (including ERM intervention limits)

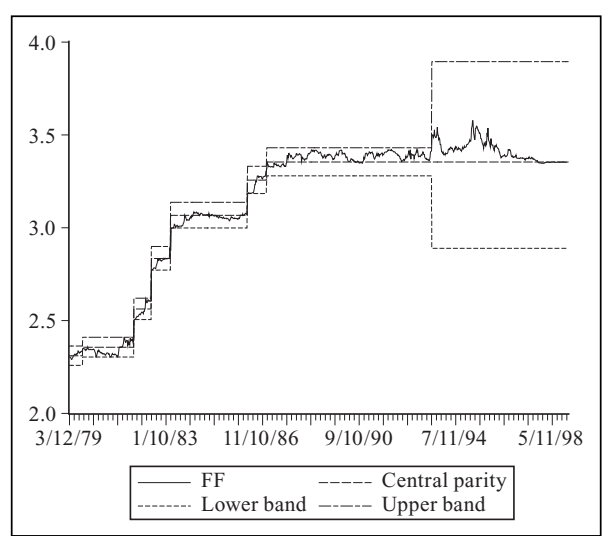


Figure 1e. HFL/DM exchange rate (including ERM intervention limits)

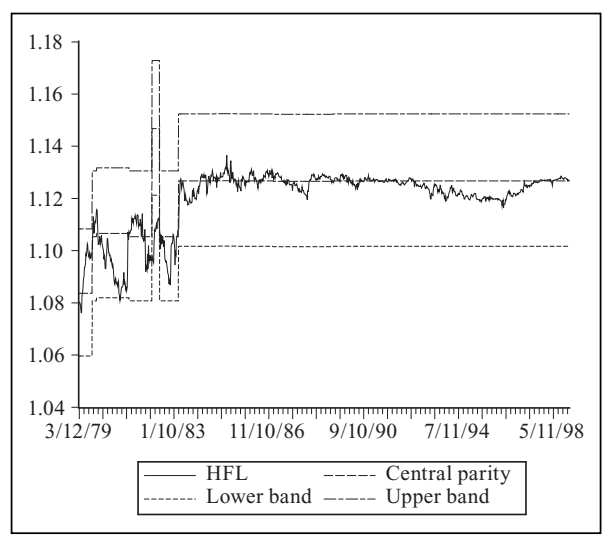

Figure 1g. LIT/DM exchange rate (including ERM intervention limits)

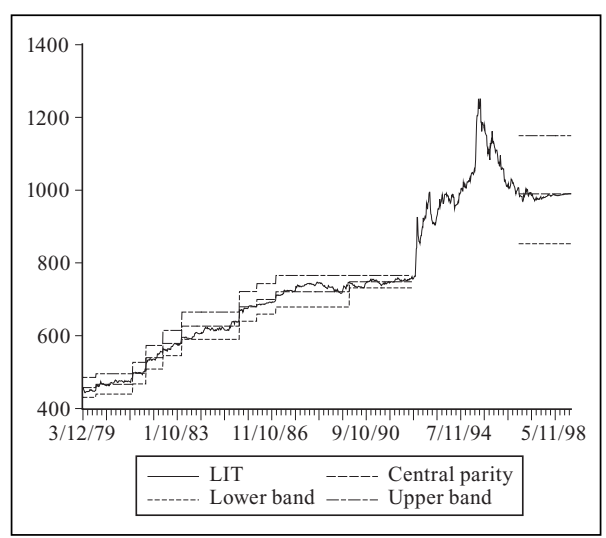

Figure 1f. IRL/DM exchange rate (including ERM intervention limits)

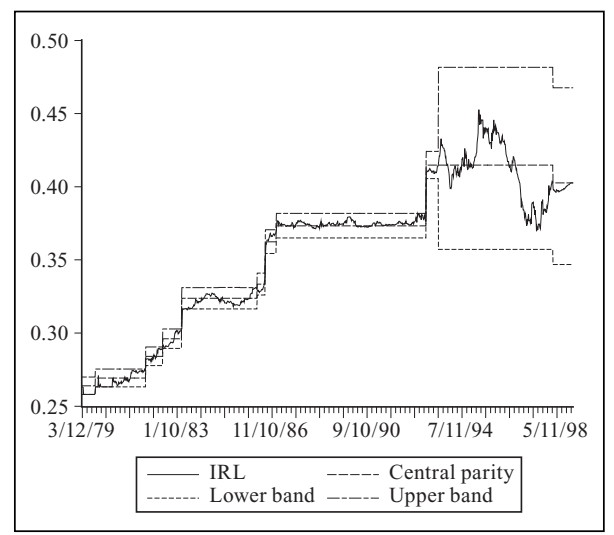

Figure 1h. PTA/DM exchange rate (including ERM intervention limits)

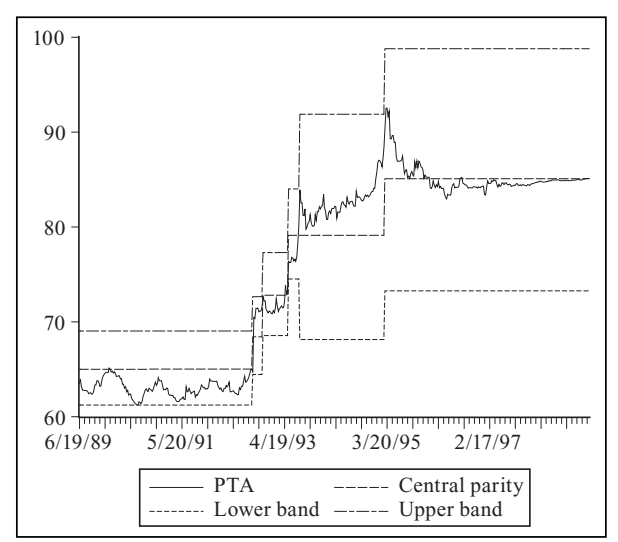

